ISSN: 1813-162X (Print) ; 2312-7589 (Online)
available online at: http://www.tj-es.com

\title{
Performance Enhancement of a Darrieus Vertical Axis Wind Turbine using Divergent Ducting System
}

\author{
Department of Electromechanical \\ Engineering \\ University of Technology \\ Baghdad \\ Iraq
}

\section{Abdullateef A. Jadallah * \\ Sahar R. Farag \\ Jinan D. Hamdi}

\section{Keywords:}

VAWT

divergent wind turbine

MATLAB

coefficient of performance

low wind speed

rotation

\section{A B S T R A C T}

Ducting system is an effective way to potentially augment the performance of wind turbine for applications in building architectures. This paper is aimed to study one of the possible enhancement method of the vertical axis wind turbine performance. It is characterized by adding divergent duct to facilitate imparting more flow rate. The divergent duct was designed and adapted with wind turbine. The system was modelled and simulated analytically and numerically. A computer program built in MATLAB 16 to simulate the performance of system. The performance and flow are also solved numerically using ANSYS-FLUENT 17.2. Two opening angles of the divergent -duct were employed to study the behavior of air flow through divergent duct and results were compared with base vertical axis wind turbine. The duct turbine with a straight wall type diffuser demonstrate power coefficient augmentation by $24.2 \%$ and $9.09 \%$ for opening angle $20^{\circ}$ and $12^{\circ}$ respectively. The optimum half opening angle was attained for the diffuser. The diffuser's length of a half of the throat opening is recommended, and its angle of opening is $20^{\circ}$. The diffuser was located in a stream-was direction that adequately aligned with the center of the vertical axis wind turbine. Results showed a reasonable influence on the performance of wind turbine. This technology may be used in gates and in urban areas with a relatively low wind speed regime.

(C) 2018 TJES, College of Engineering, Tikrit University

DOI: http://dx.doi.org/10.25130/tjes.25.3.10
Received $\quad 30$ April 2018

Accepted 25 July 2018

Available online 01 September 2018

تعزيز اداء توربين داريس الريحي عمودي المحور باستخدام منظومة معبر ناشر

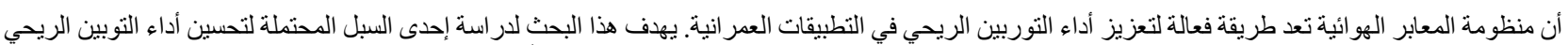

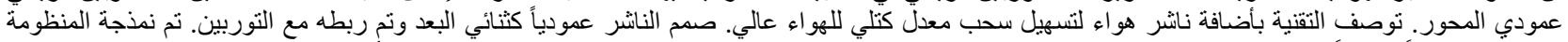

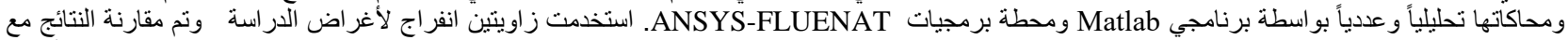

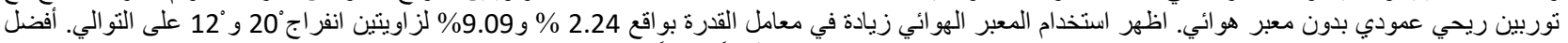

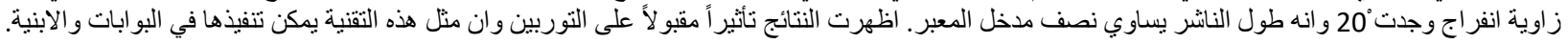

\section{INTRODUCTION}

Wind power costs have declined in recent years, and at the good wind-station sites, technologies of wind energy are currently in high competition with other power production plants Blanco [1] and Neig [2]. Considerable efforts have been made to substitute the available wind farms with more efficient farms in the wake of rapid technological developments involving the replacement of turbines with more efficient turbines for the purpose of restarting highefficiency wind farms [3]. Abdullateef et al. [4] evaluated the performance and productivity of the vertical axis wind turbine using different rotor geometry for both the Savino's and Darrieus wind turbine performance assessment of the 


\begin{tabular}{|ll|}
\hline \multicolumn{2}{l|}{ Nomenclatures } \\
$a$ & axial induction factor \\
$A$ & area, $\left(\mathrm{m}^{2}\right)$ \\
$C p$ & power coefficients \\
$C t$ & torque coefficients \\
$D_{1}$ & inlet diameter of duct, $(\mathrm{m})$ \\
$D_{2}$ & out let diameter of duct, $(\mathrm{m})$ \\
$k$ & turbulent kinetic energy, $\left(\mathrm{m}^{2} / \mathrm{sec}^{2}\right)$ \\
$L$ & duct length, $(\mathrm{m})$ \\
$P$ & pressure, $(\mathrm{Pa})$ \\
$R$ & turbine radius, $(\mathrm{m})$ \\
$T$ & time, $(\mathrm{sec})$ \\
$V_{\infty}$ & free stream velocity, $(\mathrm{m} / \mathrm{sec})$ \\
Greek & letters \\
$\phi$ & duct angle, $($ degree $)$ \\
$\varepsilon$ & area ratio \\
$\rho$ & air density, $\left(\mathrm{kg} / \mathrm{m}^{3}\right)$ \\
$\lambda$ & Tip Speed Ratio $(\mathrm{TSR})$ \\
$\Omega$ & the angular velocity, $(\mathrm{rad} / \mathrm{sec})$ \\
$\mu_{p}$ & back pressure coefficient \\
Abbreviations \\
DVAWT $\quad$ Divergent Vertical Axis Wind Turbine \\
TSR & Tip Speed Ratio \\
VAWT $\quad$ Vertical Axis Wind Turbine \\
\hline
\end{tabular}

various configuration was Van Bussel [5] analyzed the performance of VAWT employing duct and showed power increment is linearly related to mass flow boosting that is achieved by increasing the exhaust area ratio and reducing the back pressure. Shives et al. [6] used CFD to study the effect of flow separation, viscous loss, and base pressure for duct design, the pressure effect base can provide a significant improvement in performance as the performance is greatly affected by the efficiency of the diffuser, which deteriorates due to the separation of flow. Vertical axis wind turbines have a number of advantages, such as wind absorption in any direction ease of manufacturing and the stable placing of a heavy generator on the ground [7]. Numerical analysis of the flow around the vertical turbines were conducted by several researches [8-10]. The wind duct was applied to the VAWT and examined the effects of increased energy using wind tunnel experiments [11-13]. Experimental and CFD validation research by [14] possessed noticeable power boosting of a horizontal axis wind turbine with shrouded diffuser compared with the same swept area of the diffuser. It also found that the degree of the enhancement in production is highly depending on the shape and configuration of the diffuser like the length and the expanding angle. Ohya et al. [15] investigated the effect of adding flange at the diffuser exit numerically. They verified the optimal form of the flanged diffuser and demonstrated that power enhancement by a 20-30\% compared to a non-ducted wind turbine, they noticed that the addition of ring flange at the exit of the diffuser, the base pressure at the outlet plane may be declined further due to the vortex generation at the exit plane. Srensen [16] analyzed the performance agumenting of wind turbines are only achieved when the duct is precisely aligned with the wind, and the flow is no so gusty. This drawback, and other aerodynamic phenomena related to wind turbines. Turbines installed inside small shrouded inlets are also used to deliver power to wireless sensors in pipes and ducts as shown in Howey et al. [17]. The present study focuses on the performance enhancement of the ducted wind turbine by using divergent duct. The divergent was configured and simulated for different geometries aiming to understand the influence of length and sweeping on power augmentation. The flow and performance were analyzed and simulated analytically with the aid of computer program written in MATLAB and numerically utilizing the commercial CFD package ANSYS17.2.

\section{MATHEMATICAL FORMULATION}

To enhance the performance of the vertical axis wind turbine using an air diffuser and analyze it numerically and analytically. The increase in velocity at the entrance of the duct is directly related to the ratio $\varepsilon$ which is expressed as the exit area divided by the inlet area $A_{\text {out }} / A_{\text {in }}$ as shown in Fig. 1.

$$
\begin{aligned}
& V_{\text {out }}=V_{\infty}(1-a) \\
& V_{\text {rotor }}=\varepsilon V_{\text {out }}=\frac{A_{\text {out }}}{A_{\text {in }}} V_{\text {out }}
\end{aligned}
$$

Combining Eqs. (1) and (2), the velocity $V$ at the inlet of the divergent can be expressed as a function of the freestream velocity $V_{\infty}$ as in the following equation.

$$
\begin{aligned}
& V_{\text {rotor }}=\varepsilon V_{\infty}(1-a) \\
& V_{\text {out }}=\mu_{p} V_{\infty}
\end{aligned}
$$

where $\mu_{p}$ back pressure coefficient [18]. In order to calculate the pressure at rotor and any point in duct.

$P=P_{a t m}+\left(1-\varepsilon^{2} \mu_{p}^{2}\right) \frac{1}{2} \rho V_{\infty}^{2}$

The thrust coefficient for the rotor is calculated by Eq. (6):

$C_{\text {T.rotor }}=4 a(1-a)$

The power and the thrust coefficient can be derived basing on the rotor area and the exit area of the divergent part respectively:

$$
\begin{aligned}
& C_{\text {T.total }}=4 \mu_{p} \varepsilon a(1-a) \\
& C_{\text {P.rotor }}=4 \varepsilon \mu_{p} a(1-a)^{2} \\
& C_{\text {P.out }}=4 \mu_{p} a(1-a)^{2}
\end{aligned}
$$

A breakdown of the thrust coefficient shows [19]:

$$
C_{\text {T.Diffuser }}=C_{\text {T.total }}-C_{\text {T.rotor }}=4\left(\varepsilon \mu_{p}-1\right) a(1-a)
$$

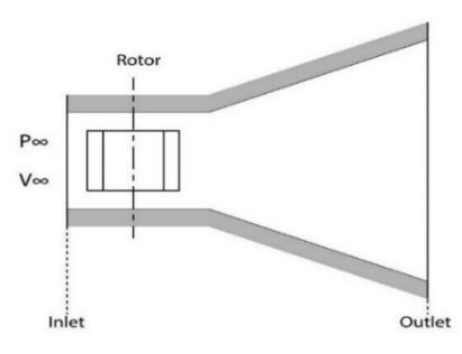

Fig. 1. Diffuser ducting system. 


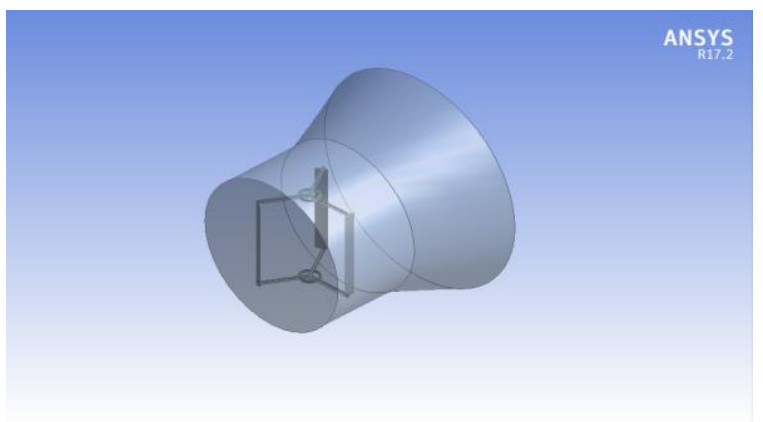

Fig. 2. Diffuser ducting system.

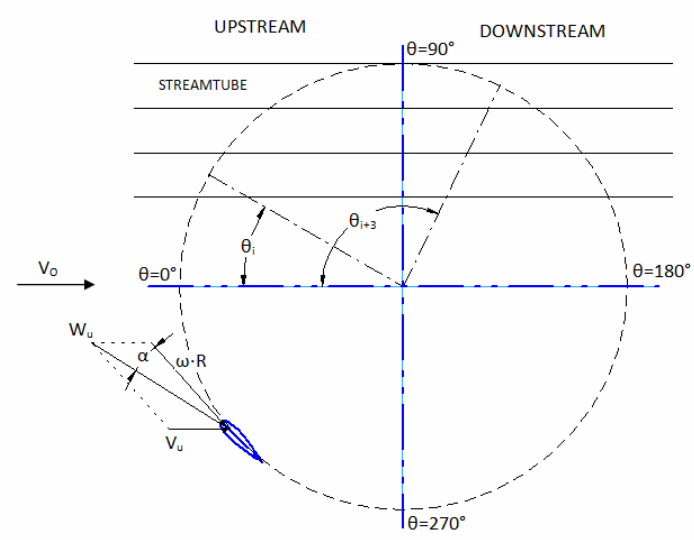

Fig.3. Discretization of the swept area of the rotor into stream tubes, velocities and flow blade angles [20].

\subsection{Analysis of the Vertical Axis Wind Rotor}

In correspond-dance to Paraschivoiu [21] the velocity induced reduced in the horizontal stream tube direction, thus the induced velocity at upstream sector of the rotor is: $\mathrm{V}_{u}=\mathrm{V}_{o} \times a_{u}$

As the free stream velocity is higher than the upstream velocity, so $a_{u}$ is less than 1 . The downstream velocity at the downstream part is:

$$
\mathrm{V}_{d}=\mathrm{V}_{o} \times\left(2 a_{u}-1\right) \times a_{d}
$$

Interference factor at downstream $a_{d}$ is smaller than that of the upstream part. The local tip speed ratio is defined as:

$\lambda_{u}=R \times \frac{\omega}{V u}$

The formula for calculating the angle of attack for the blade is:

$$
\alpha=\arcsin \left(\frac{\cos (\theta) \cos \left(\alpha_{o}\right)-\left(\lambda-\sin (\theta) \sin \left(\alpha_{o}\right)\right.}{\sqrt{\left[\left(\lambda_{u}-\sin (\theta)\right)^{2}+\left(\cos (\theta)^{2}\right)\right]}}\right)
$$

The normal and tangential coefficients can be calculated from

$$
\begin{aligned}
& \mathrm{C}_{n}=C_{l} \cos (\alpha)+C_{d} \sin (\alpha) \\
& \mathrm{C}_{t}=C_{l} \sin (\alpha)-C_{d} \cos (\alpha)
\end{aligned}
$$

The up-wind flow conditions are specified by $\mathrm{F}_{\mathrm{up}}$ :

$\mathrm{F}_{\mathrm{up}}=\frac{B \times c}{8 \pi R} \int_{-0.5 \pi}^{0.5 \pi}|\sec \theta|(C n \times \cos \theta-C t \times \sin \theta) d \theta$
The upstream induction factor is:

$a_{u}=\frac{\pi}{\mathrm{F}_{\mathrm{up}}+\pi}$ follows:

The torque produced by a blade is computed as $T(\theta)=0.5 \rho c R h C t$

$$
\times V_{u}^{2}\left[\left(\lambda_{u}-\sin (\theta)\right)^{2}+\left(\cos (\theta)^{2}\right)\right]
$$

The upstream average torque is estimated by averaging the contribution of torque of each stream tube:

$$
\operatorname{Tav}=\frac{B}{2 \pi} \int_{-0.5 \pi}^{0.5 \pi} T(\theta) d(\theta)
$$

The non-dimensional average torque coefficient $C_{\mathrm{t}}$ is then calculated from:

$C_{\text {tuav }}=\frac{T a v}{0.5 \rho V_{0}^{2} A R}$

Finally, the power coefficient of the upstream half $C \mathrm{p}_{\mathrm{u}}$ may be determined as:

$$
C p u=C t u a v \times \lambda_{u}
$$

Similarly, the downstream power coefficient $\left(C p_{\mathrm{d}}\right)$ and average torque $\left(C t_{\mathrm{d} a v}\right)$ of the VAWT rotor are obtained. The overall coefficient of power $(C p)$ for the VAWT rotor is the summation of the up wind and down wind power coefficients:

$C \mathrm{p}=C \mathrm{p}_{u}+C \mathrm{p}_{d}$

A computer code is built in MATLAB. It is summarized in the flow chart shown in Fig. 4.

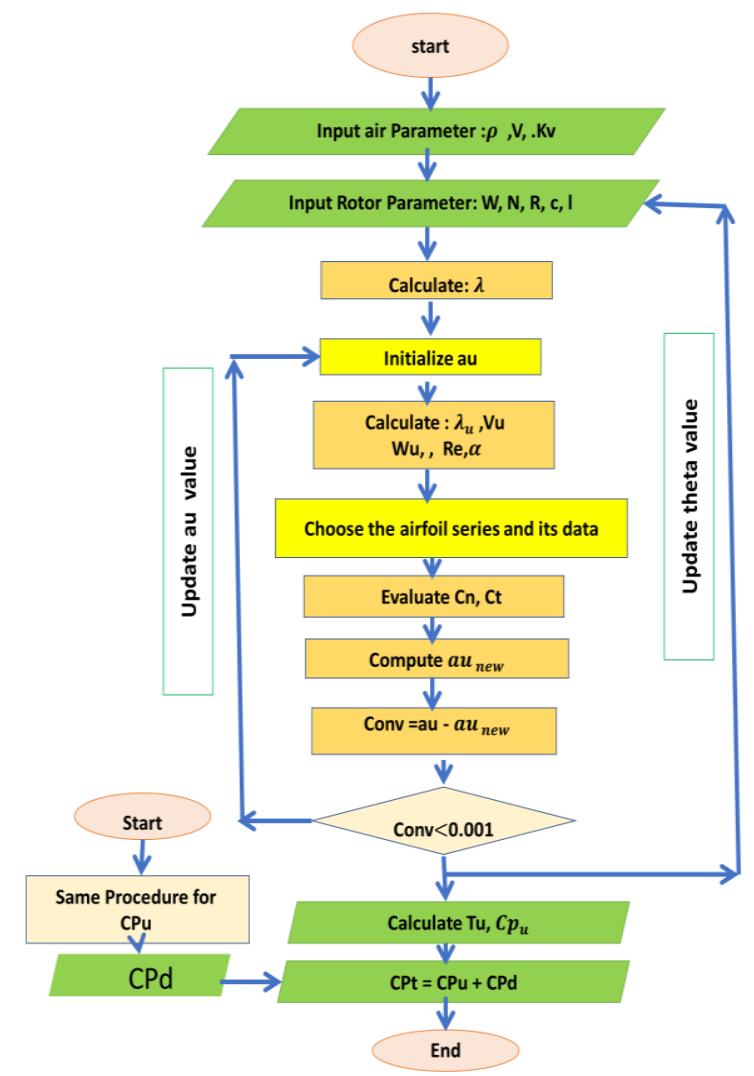

Fig. 4. Flow chart of VAWT model. 


\section{NUMERICAL ANALYSIS OF THE CONVERGENT DUCT WIND TURBINE}

The process of generating the 2D CFD model was done inside the ANSYS workbench multi-physics platform with the ANSYS package where it is possible to develop a workflow. ANSYS Fluent 17.2 is used to simulate and predict the fluid flow velocity and the other important parameter such as pressure.

\subsection{Geometry}

Darrius 3-bladed wind rotor is considered in this study. 0012 NACA series is employed the twodimensional airfoil of the three blades are set in the domain and separated by $120^{\circ}$.The divergent ducting system is opened by two angles these angles are $20^{\circ}$ and $12^{\circ}$ for duct length $75.5 \mathrm{~cm}$ and $129.3 \mathrm{~cm}$ respectively and inlet and outlet diameter $145 \mathrm{~cm}$ and $200 \mathrm{~cm}$ respectively for both duct.

\subsection{Generation of Mesh}

The accuracy of result depends on the mesh size and distribution. In the present $2 \mathrm{D}$ simulations, the mesh is very fine around the blades in order to give the rat flow behavior in this region as shown in Fig. 6. Table 1 show meshing characteristics.

\subsection{Boundary Condition}

The boundary condition in this study has been summarized in Table 2.

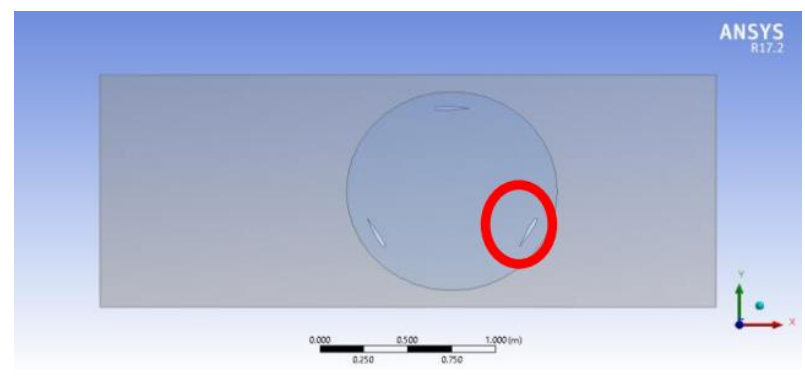

(a) Vertical axis wind turbine.

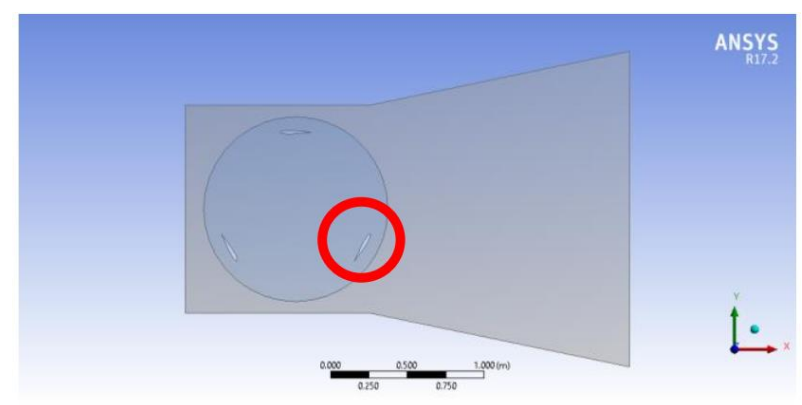

(b) Divergent duct wind turbine at open angle $12^{\circ}$.
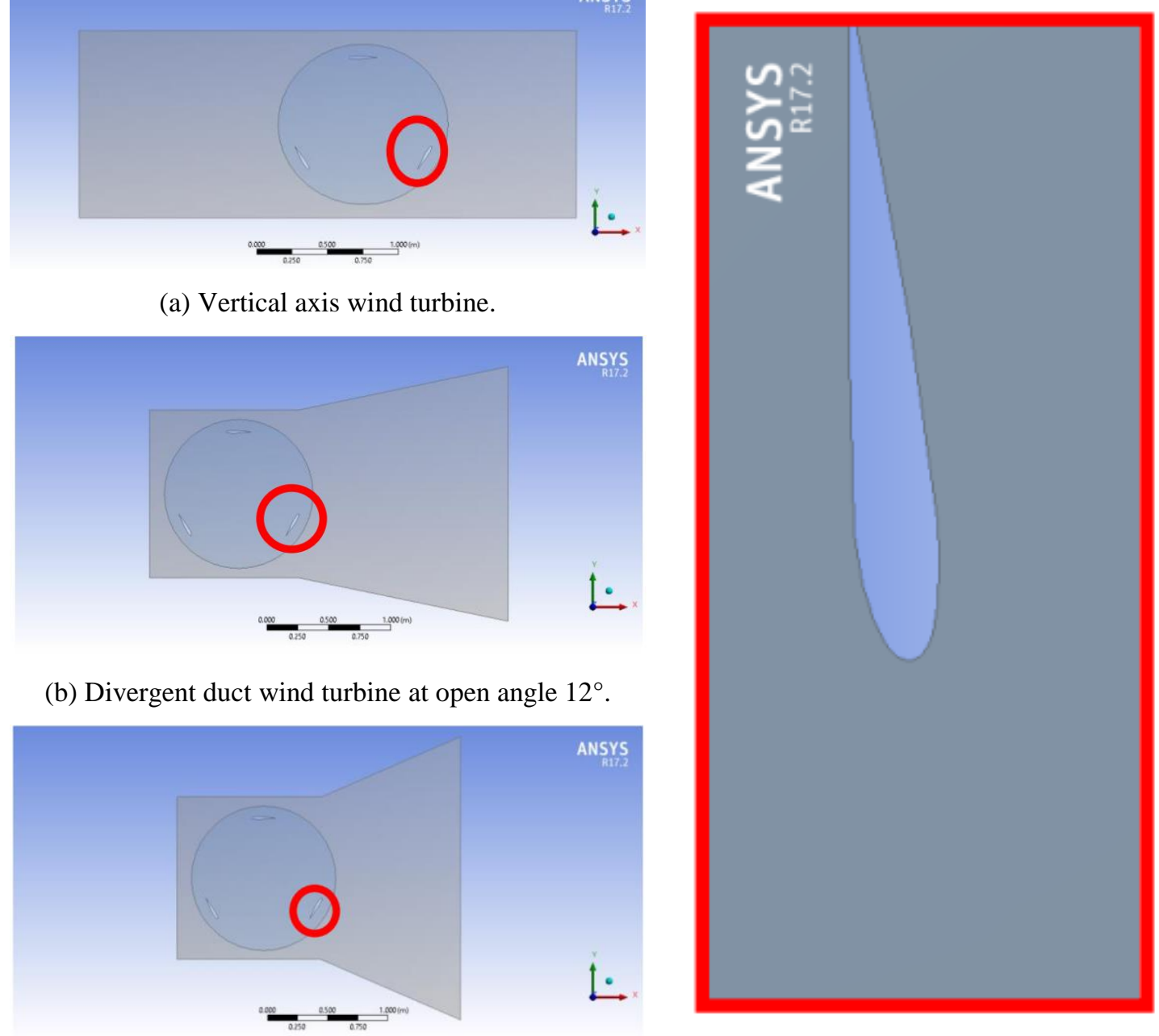

(c) Divergent duct wind turbine at open angle $20^{\circ}$.

(d) Blade.

Fig. 5. 2D Geometries of the ducted vertical axis wind turbine.

Table 1

Characteristics of meshing characteristics.

\begin{tabular}{lllll}
\hline No. of nodes & No. of elements & Average element quality & Average value of skewness & Minimum \\
\hline 67582 & 66704 & 0.88242 & 0.12652 & $2.4379 \times 10^{-5}$ \\
\hline
\end{tabular}




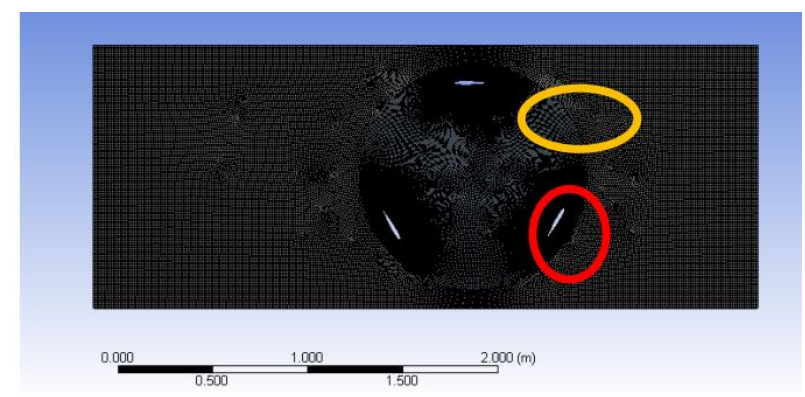

(a) Vertical axis wind turbine.
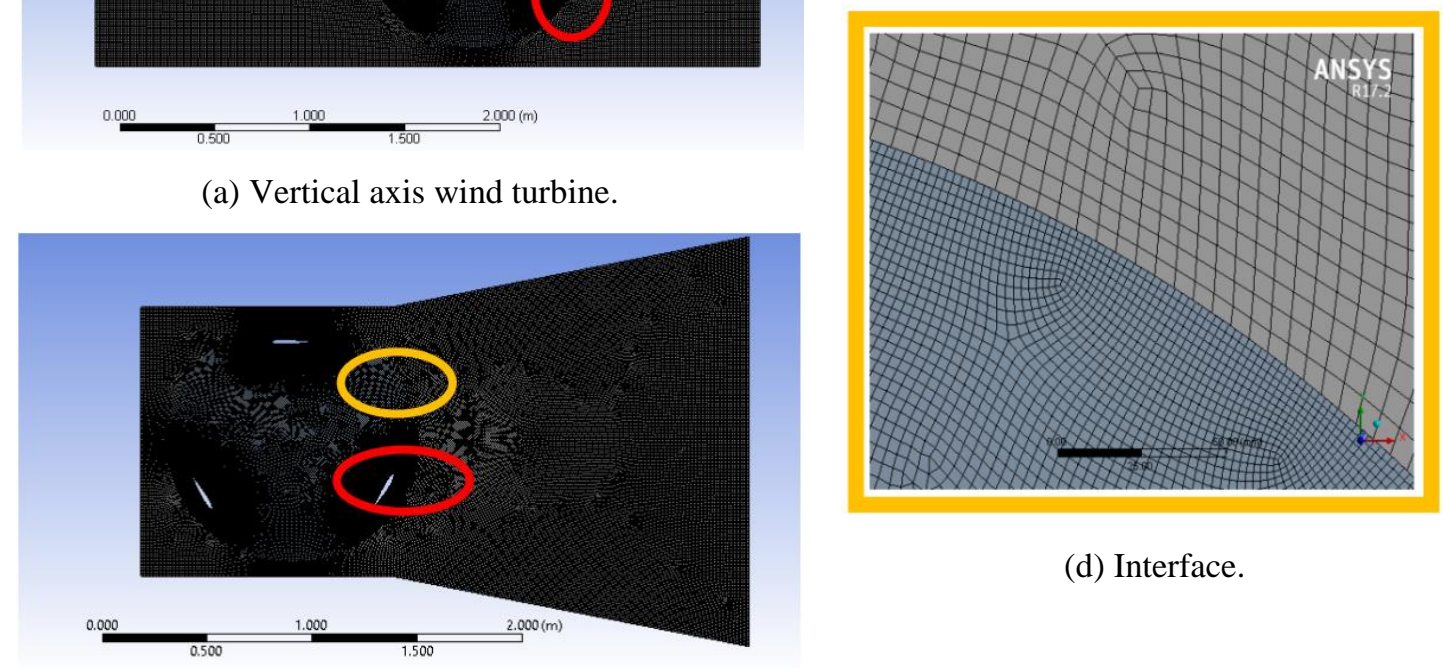

(d) Interface.

(b) Divergent duct wind turbine at open angle $12^{\circ}$.
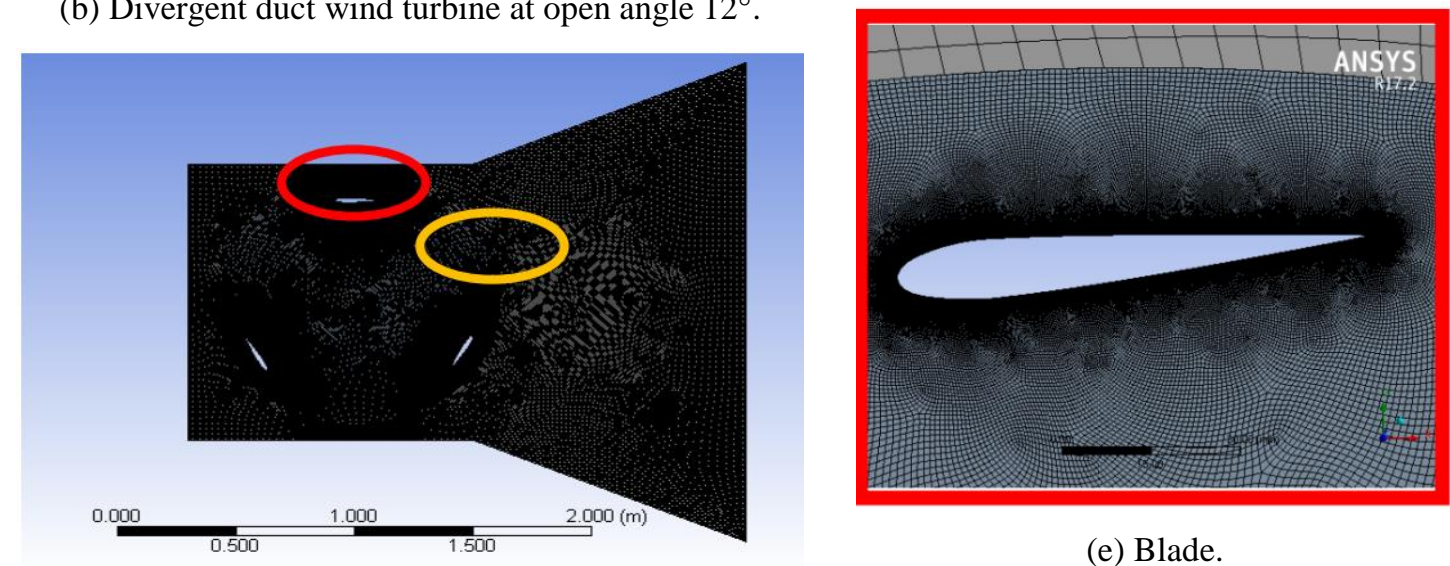

(e) Blade.

(c) Divergent duct wind turbine at open angle $20^{\circ}$.

Fig. 6. 2D Meshing of duct vertical axis wind turbine.

Table 2

Outline of the boundary conditions.

\begin{tabular}{ll}
\hline Viscous model & State \& Value \\
\hline Model & $k-\omega$ \\
$k-\omega$ & SST \\
Model constants & Default \\
Inlet boundary condition & \\
Type & Inlet velocity \\
\hline Velocity magnitude $(\mathrm{m} / \mathrm{s})$ & 10 \\
Reference frame & Absolute \\
Turbulent method specification & Ratio of intensity and viscosity \\
Outlet boundary condition & \\
Type & Pressure outlet \\
\hline Gage pressure $(\mathrm{Pa})$ & 101325 \\
Back flow direction specification method & Normal to boundary \\
Turbulent specification method & Magnitude normal to boundary \\
\hline
\end{tabular}




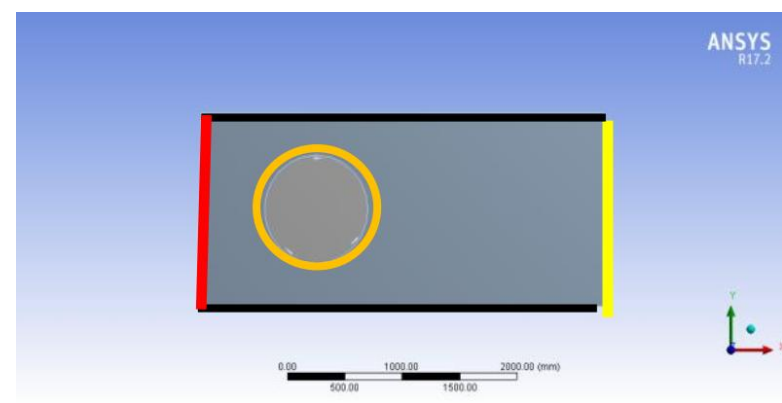

(a) Vertical axis wind turbine.

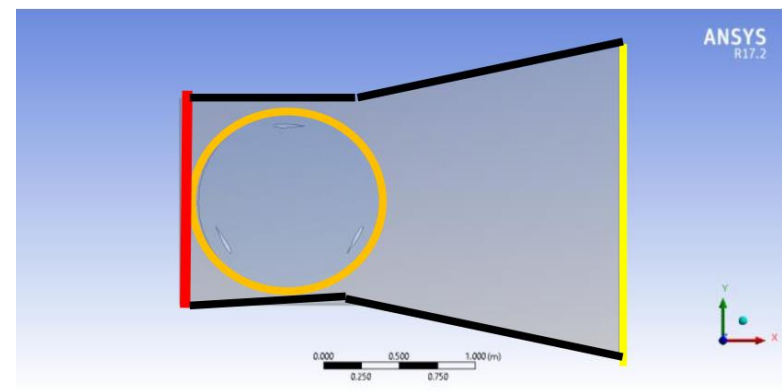

(b) Convergent duct wind turbine.

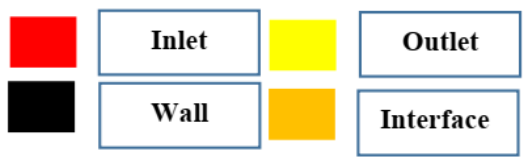

Fig. 7. Computational domain and boundary conditions.

\subsection{Setup of the Problem in Fluent}

Hexahedral (rotating) mesh of the wind rotor is installed with the stationary mesh of the far aft-field. Hence, the mesh is tested into ICEM CFD for all maybe errors such non-connected vertices, periodicity, no covered faces are single elements. ANSYS is utilized as a frequent structural solver tool and Fluent as an output tool for solving and to write a mesh file which could be recognized by FLUENT. 2D double precision solver and parallel processing was employed. Mesh is then inspected again in fluent for any possible negative volumes and appeared skewness. FLUENT also permits scaling the working domain size and at the same instance the user could state the units in SI, CGS format etc. To apply the periodicity turbo-outer and far-inner mesh, both parts are altered from wall boundary types to interface the boundary kinds. Mesh interface is generated by choosing the interface zones which facilitate setting the periodic rotational boundary conditions. The application of semi implicit method of pressure linked pressure (simple) scheme is considered in this study. Amongst many schemes of discretization available in FLUENT, Greengrass node-based gradient with a Presto pressure and $2^{\text {nd }}$ order upwind scheme is appeared to be suitable for the present study. Simulation starts with the $2^{\text {nd }}$ upwind scheme and continues with the second order after the first convergence is achieved. This is to avoid possibly accrued instability in flow.

\subsection{Time Step Calculations}

Unsteady state simulation involves the time dependent calculations. Time step is computed using the rotor rotational. The maximum iterations processed in a time step in FLUENT principally sets the maximum iterations to be carried out in a time step, which is obviously implemented for the calculations of unsteady flow. If the convergence criteria are reached before this particular number of iterations is done, the solution transfers to the next time step. Therefore, it is immensely recommended to govern the value of maximum iterations per step relatively high.

\subsection{Reference Values}

Chord's length $=0.1 \mathrm{~m}$.

Length $($ reference $)=$ Radius of the rotor $=0.5 \mathrm{~m}$.

Enthalpy $=0 \mathrm{~J} / \mathrm{kg}$.

Pressure $=101325$ pa at the velocity inlet.

Density $=1.2256 \mathrm{~kg} / \mathrm{m}^{3}$.

Temperature $=288.16 \mathrm{~K}$.

\subsection{Independence of the Grid}

Results achieved from CFD simulation should be grid independently. So, the results must not vary with the number of the mesh cells. Thus, grid independence is considered as one of the effective parameters to test the accuracy of the solution. Simulation run for a minimal cell size of $0.295690 \mathrm{~mm}$ and $\max$ face size $29.5690 \mathrm{~mm}$. Number of nodes and element equal 67582 and 66704, respectively.

\section{RUSTLE AND DISCUSSION}

Vertical axis wind turbine (Darrieus-3 blade) type with adaptive diffuser duct was modeled, Simulated and evaluated analytically and numerically. Figs. 8 and 9 show the velocity and pressure distribution along divergent duct for different length and open angle this show the maximum velocity and maximum drop in pressure accurse when the open angle $20^{\circ}$ and the length 0.52D1. Figs. 10 and 11 Show velocity distribution and pressure difference between the upper and lower surface of airfoil. The result showed that the velocity of the wind passing over the upper surface of the airfoil is more than the one passing over the lower surfaces of the airfoil this whole mechanism eventually leads to an aerodynamic lift generation. In case of wind mills, the aerodynamic lift force causes rotation of the turbine blades and in turn increase the power produced. Exact pressure analysis on divergent duct and turbine blade by CFD for different open angle and length of diffuser shown in Figs. 12 and 13 in both cases a low-pressure region was created in the inlet of divergent duct, the pressure at the entrance of the duct is directly related to the area ratio $\varepsilon$. Which is responsible to draw more air flow through divergent duct, its results increment in velocity throughout the divergent section shown in Figs. 14 and 15. The result from mathematical model and ANSYS shown in Figs. 16 and 17 they present the coefficient of performance a variation with the TSR for different opening angles of the duct .The divergent length $L$ was 0.8917 Din and 0.5206 Din, for open angle $12^{\circ}$ and $20^{\circ}$ respectively, and the duct is well set and aligned with the wind rotor .Results showed that increasing opening of the duct up to a half angle of $20^{\circ}$ lead to generate more power output as compared with the non-ducted vertical axis wind turbine Figs. 18 and 19 
shows the comparison of the performance coefficient of the numerical solution by the 2D-ANSYS-FLUENT 17.2 , and the analytical solution by MATLAB program where we called for an acceptable agreement in the results.

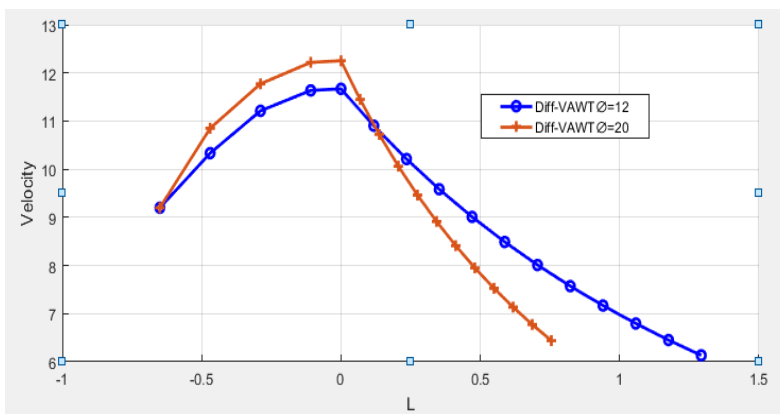

Fig. 8. Velocity disterbution along the divergent duct for different open angle.

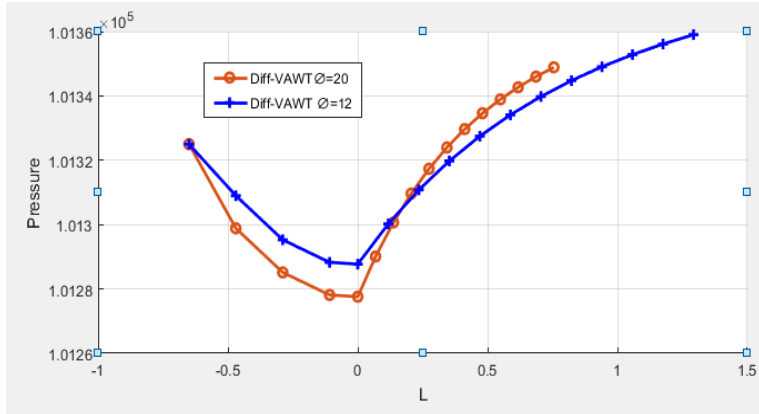

Fig. 9. Pressure disterbution along the divergent duct for different open angle.

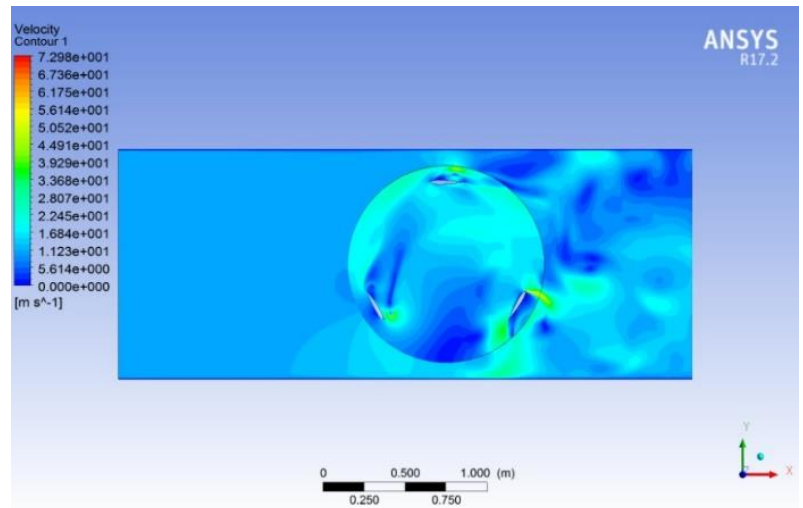

Fig. 10. Velocity distribution through vertical axis wind turbine.

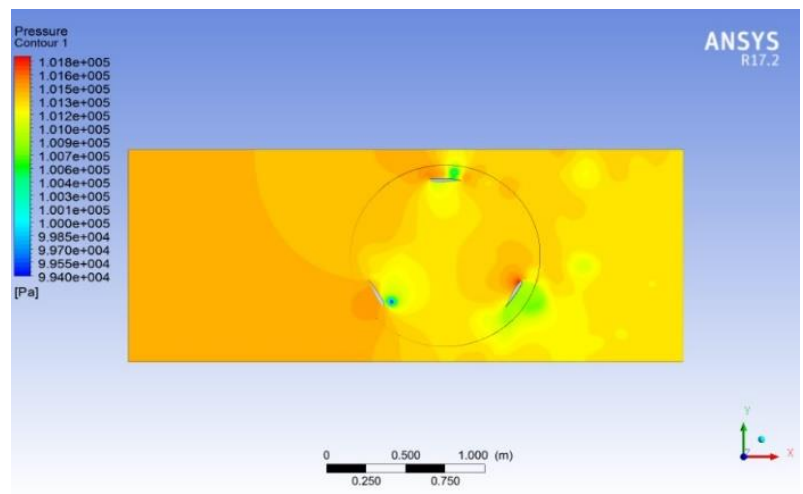

Fig. 11. Pressure contour of the rotor of the conventional vertical axis wind turbine.

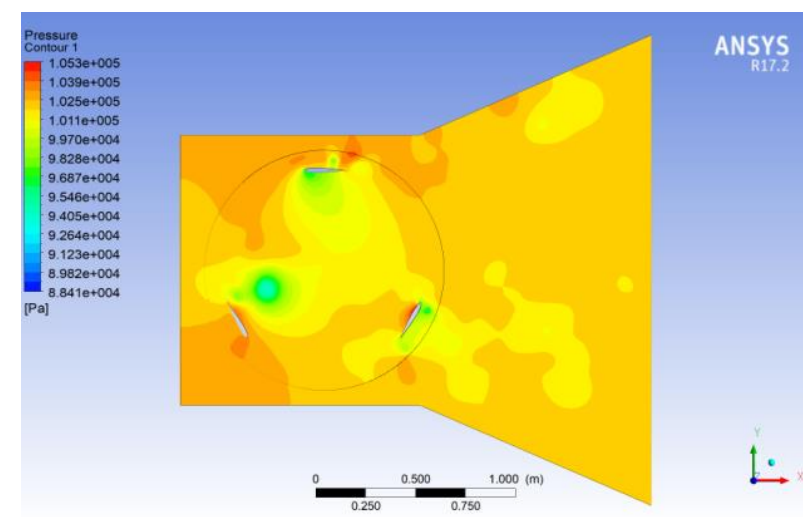

Fig. 12. Pressure distribution in divergent duct for opening angle $20^{\circ}$.

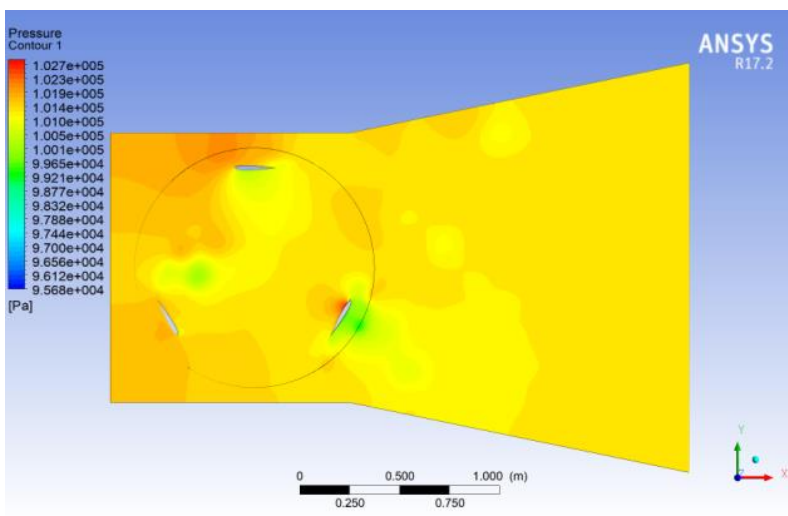

Fig. 13. Pressure distribution in divergent duct for opening angle $12^{\circ}$.

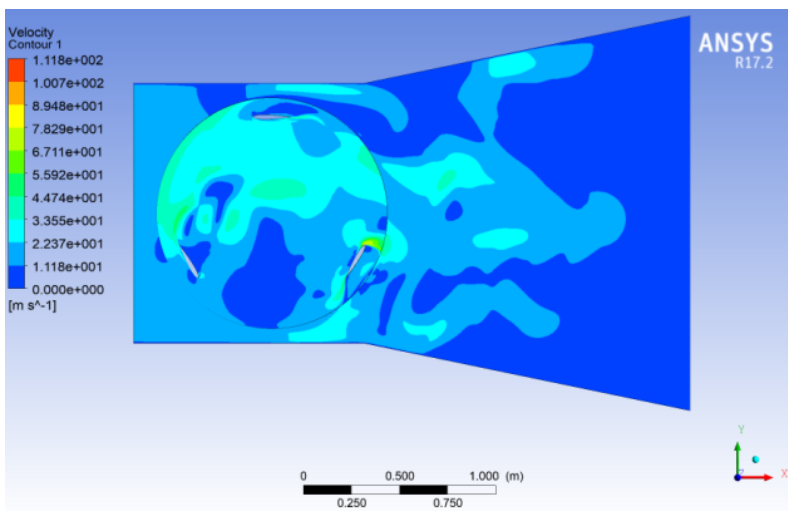

Fig. 14. Velocity distribution in divergent duct for opening angle $12^{\circ}$.

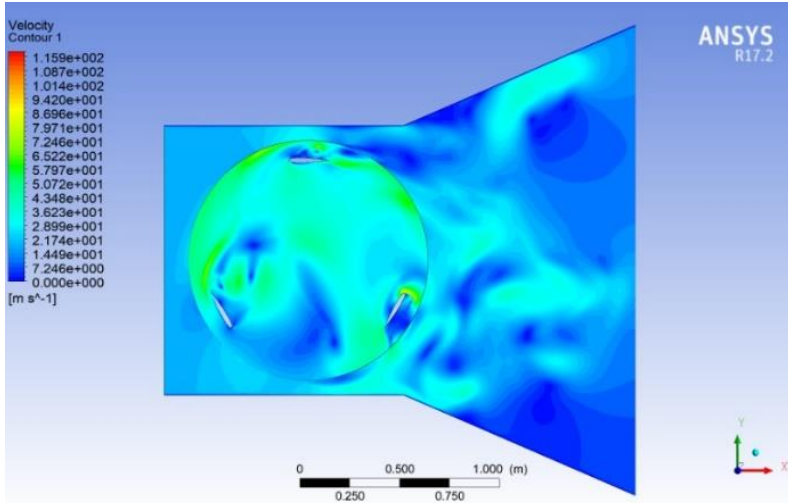

Fig. 15. Velocity distribution in divergent duct for opening angle $20^{\circ}$. 


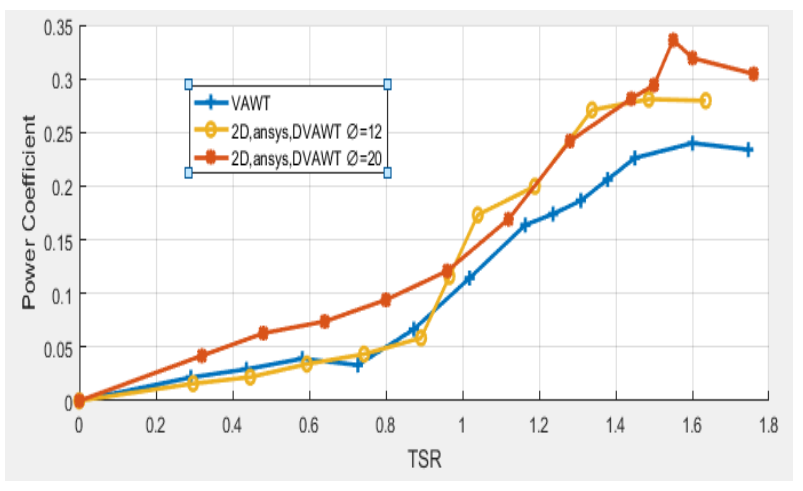

Fig. 16. Coefficient of performance dependence on $\lambda$ with and without divergent duct.

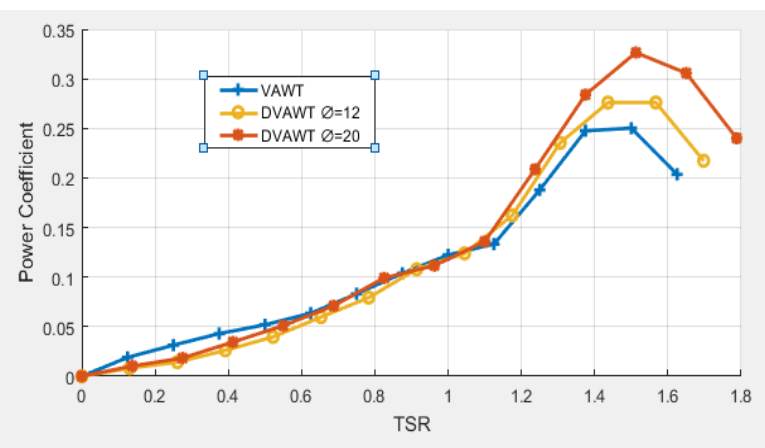

Fig. 17. Change in power coefficient with $\lambda$ with and without divergent duct.

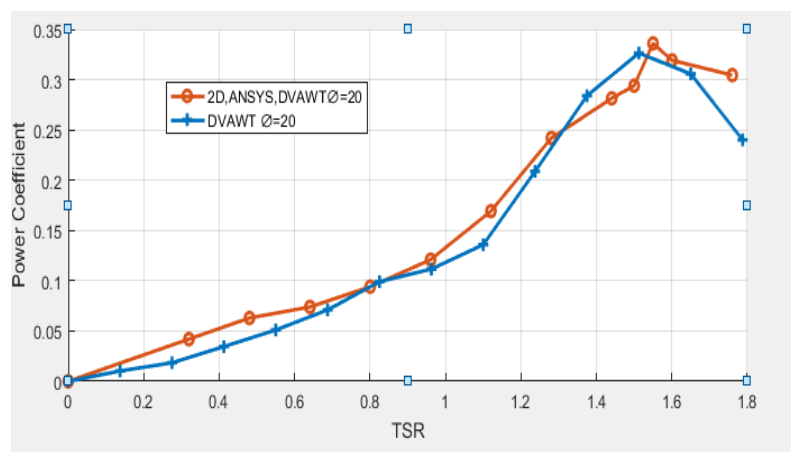

Fig. 18. The $C p$ variation with $\lambda$ for open angle $20^{\circ}$.

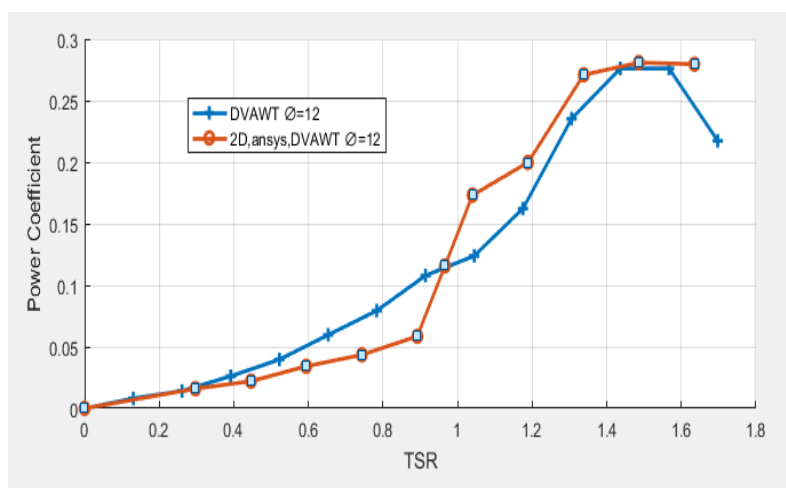

Fig. 19. Power coefficient variation with TSR for open angle $12^{\circ}$.

\section{CONCLUSIONS}

Numerical and analytic predication of the performance of the ducted vertical axis wind turbine (Darrius-three blades) was achieved in this work.
Employing an adaptable divergent duct enhances the performance of the duct VAWT by $24.2 \%$ and $9.09 \%$ for opening angle $20^{\circ}$ and $12^{\circ}$ respectively. This is due to the accessibility to impart more flow rate. This technology may be considered as a promising are especially when it will be used in urban and law wind speed regimes utilizing the gates and structures providing such passages.

\section{REFERENCES}

[1] Blanco MI. The economics of wind energy. Renewable and Sustainable Energy Reviews 2009; 13 (6-7): 1372-1382.

[2] Neij L. Cost development of future technologies for power generation-A study based on experience curves and complementary bottom-up assessments. Energy Policy 2008; 36 (6): 2200-2211.

[3] Phillips DG. An investigation on diffuser augmented wind turbine design. PhD Thesis, The University of Auckland; 2003.

[4] Jadallah AA, Mahmoud DY, Farhan HA. Performance evaluation of the vertical axis wind turbine with various rotor geometries. Al-Qadisiya Journal for Engineering Sciences 2016; 9 (4): 571584.

[5] Van Bussel GJ. The science of making more torque from wind: Diffuser experiments and theory revisited. Journal of Physics: Conference Series: IOP Publishing; 2007. pp. 012010.

[6] Shives M, Crawford C. Developing an empirical model for ducted tidal turbine performance using numerical simulation results. Proceedings of the Institution of Mechanical Engineers, Part A: Journal of Power and Energy 2012; 226 (1): 112-125.

[7] Watanabe K, Takahashi S, Ohya Y. Application of a diffuser structure to vertical-axis wind turbines. Energies 2016; 9 (6): 406-412.

[8] Li C, Zhu S, Xu Y-1, Xiao Y. 2.5 D large eddy simulation of vertical axis wind turbine in consideration of high angle of attack flow. Renewable Energy 2013; 51: 317-330.

[9] Lanzafame R, Mauro S, Messina M. 2D CFD modeling of $\mathrm{H}$-Darrieus wind turbines using a transition turbulence model. Energy Procedia 2014; 45: 131-140.

[10] Shamsoddin S, Porté-Agel F. Large eddy simulation of vertical axis wind turbine wakes. Energies 2014; 7 (2): 890-912.

[11] Watanabe K, Ohya Y, Karasudani T, Watanabe K. Application of collection-acceleration device of wind to VAWT. The Japan Wind Energy Symposium. 2004, 20 November; Tokyo, Japan: pp. 147-150, 2004.

[12] Takahashi S, Ohya Y, Karasudani T, Watanabe K. Numerical and experimental studies of Airfoils suitable for vertical axis wind turbines and an application of wind-energy collecting structure for higher performance. The Fourth International Symposium on Computational Wind Engineering (CWE 2006). 2006, 16-19 July; Yokohama, Japan: pp. 327-330.

[13] Watanabe K, Ohya Y, Karasudani T. Development of a high-performance vertical axis wind turbine by a drive. The National Symposium on Wind Enginee- 
ring. 2010, 1-3 December; Tokyo, Japan: pp. 239244.

[14] Jafari SA, Kosasih B. Flow analysis of shrouded small wind turbine with a simple frustum diffuser with computational fluid dynamics simulations. Journal of Wind Engineering and Industrial Aerodynamics 2014; 125: 102-110.

[15] Ohya Y, Karasudani T, Sakurai A, Abe K-i, Inoue M. Development of a shrouded wind turbine with a flanged diffuser. Journal of Wind Engineering and Industrial Aerodynamics 2008; 96 (5): 524-539.

[16] Sørensen JN. Aerodynamic aspects of wind energy conversion. Annual Review of Fluid Mechanics 2011; 43: 427-448.

[17] Howey DA, Bansal A, Holmes AS. Design and performance of a centimetre-scale shrouded wind turbine for energy harvesting. Smart Materials and Structures 2011; 20 (8): 085021.

[18] Geurts B, Simao Ferreira C, Van Bussel G. Aerodynamic analysis of a vertical axis wind turbine in a diffuser. 3rd EWEA Conference-Torque. 2010, 23-25 November; Carlos Simão Ferreira; pp. 1-7.

[19] Van Dorst FA. An improved rotor design for diffuser augmented wind turbine. MSc. Thesis, Eindhoven University of Technology, 2011.

[20] Castillo J. Small-scale vertical axis wind turbine design. BSc. Thesis, Tampere University of Applied sciences, 2011.

[21] Paraschivoiu I. Wind turbine design: with emphasis on Darrieus concept: Presses inter Polytechnique; 2002. 